\title{
An anniversary edition to mark a successful 2 nd year
}

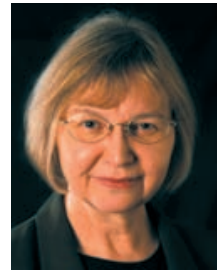

P.L. Haslam

Breathe Chief Editor, September 2005-September 2006

Chair, ERS School, September 2005-September 2008

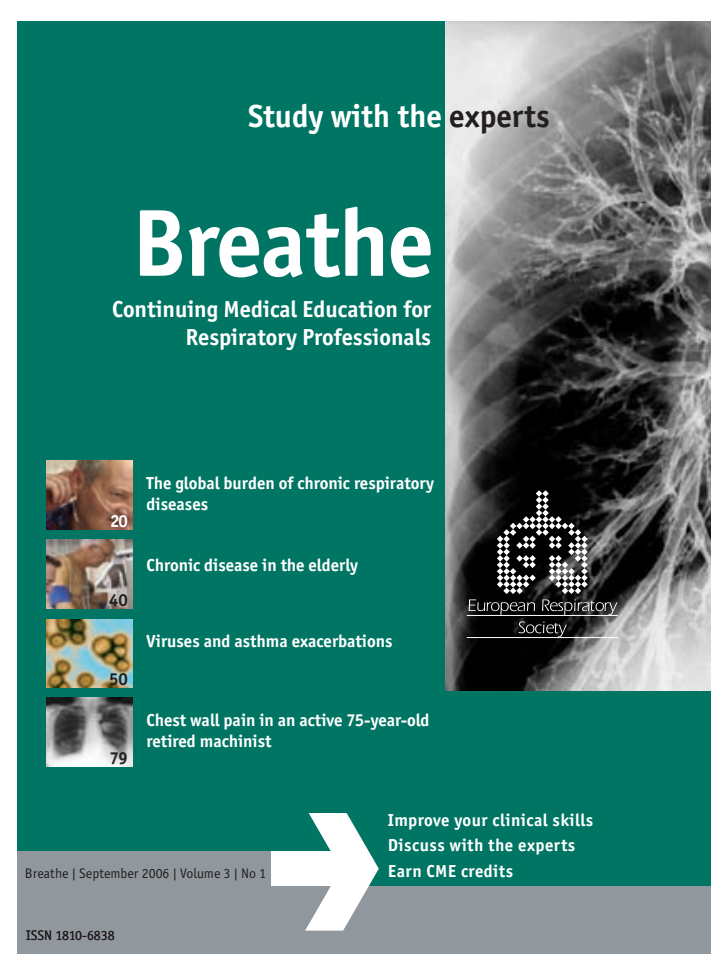

【 The last 12 months have proved an eventful year for Breathe. When I took over as Chief Editor at the start of the journal's 2nd year, in September 2005, this young educational journal was still an unofficial publication undergoing its trial period to prove its worth to the European Respiratory Society (ERS) membership. Therefore, one of my main challenges was to make further improvements sufficient to justify that Breathe should be accepted as an official publication of the ERS. It is thus to the credit of all those who contributed to the development of this journal, that a membership survey in December 2005 provided overwhelming support for the continuance of Breathe, leading to it being officially approved by the ERS Executive Commitee in February 2006. Many of those who contributed during this formative period were acknowledged in a previous editorial, and I now give special thanks to those who formulated the original business plan, namely Michael Gallico (Maney Publishing) and Jean-Luc Eiselé (ERS).

The main challenge now is to establish Breathe as the leading educational journal for training and continuing medical education (CME) and professional development in respiratory medicine globally. This is already facilitated by the journal being open access and freely available on the ERS website. Furthermore, the journal is also a leader in providing articles which allow readers to obtain CME accreditation.

We are also proud that the journal is attracting increasing numbers of high-quality reviews from experts of wide international repute. This is especially evident in the contents of this 2 nd anniversary issue.

\section{This issue}

The President of the ERS, Giovanni Viegi, has worked tirelessly during his term of office to find ways to resolve the problem that the serious consequences of chronic respiratory diseases are not fully recognised by the international community, politicians and the public. He has inspired a Europe-wide campaign through the ERS membership and the Forum of European Respiratory Societies (FERS) for inclusion of respiratory diseases amongst the list of chronic diseases in the EU 7th Framework Programme. In this issue of Breathe, we are, therefore, delighted to include a review from Giovanni Viegi and his colleagues from Pisa (Italy) to give readers a state-of-the-art educational update on the global burden of chronic respiratory diseases. This review is full of data that we hope you find useful not only for your own educational benefit but also to assist you in the continuance of efforts to raise the public profile of respiratory diseases.

The problem of chronic diseases in the elderly, especially the recognition and management of co-morbidities, is another topic where there is a need to considerably raise awareness and improve the standards of medical education and patient care. These problems are explained in the review by the Vice-President of the ERS Leo Fabbri (Modena, Italy) and his colleague Roberto Ferrari, a cardiologist, from Ferrara (Italy). As they point out, modern medicine still tends to focus on assessing the severity of single chronic diseases; however, more than half of elderly people $(\geq 65)$ have at least three chronic medical conditions. In the respiratory field, chronic obstructive pulmonary disease (COPD) is described as a prime example of a condition where co-morbidities are 
highly likely to affect health outcomes. In particular, COPD patients are more likely to die from cardiovascular complications or cancer than from respiratory failure. This comprehensive review describes a wide range of co-morbidities that the respiratory physician is likely to encounter. Improved strategies to recognise, manage and educate about co-morbidities are clearly needed.

We are also privileged to include a review by a renowned international expert in respiratory physiotherapy, Rik Gosselink, from Leuven (Belgium). There is increasing evidence that patients with a variety of conditions affecting the respiratory system can benefit from including physiotherapy as part of their treatment in addition to conventional medical management. In his excellent review, Rik Cosselink describes the benefits that selected patients can gain by employing an appropriate physiotherapy treatment approach.

Another important review in this edition of Breathe is the article from Apostolos Bossios and Nikolaos G. Papadopoulos, contributors from Sweden and Greece, entitled "Viruses and asthma exacerbations". This paper does a great job at emphasising the role of respiratory viruses in triggering acute asthma exacerbations in both children and adults. Furthermore, it explains the current knowledge about the underlying mechanisms, although incomplete, and the subsequent possibilities for intervention

This issue also contains several 'hottopic' articles and several case reports covering a diversity of subjects. The case report by M. Thirumaran and Martin F. Muers was specially commissioned to develop a style for the journal to further improve the educational value of these 'cases for diagnosis'. I thank the authors for their success in maximising the educational value and I hope future contributors will use this as an example when preparing new cases for submission.

\section{Syllabus in respiratory medicine}

The above would be sufficient content for most issues of Breathe, but this 2nd anniversary issue is indeed special. A highlight of this issue is that it also contains the first document produced by the HERMES Task Force, giving the results of the successful completion of the 1st year's work to produce a consensus-based 'European Core Syllabus in Respiratory Medicine'. The HERMES project aims to achieve better harmonised education and training in respiratory medicine for European Specialists. It is one of the most important educational projects currently being undertaken by the ERS together with other key partners. I am privileged to be a member of the task force and we hope this report will become essential reading for all specialists and trainees and for all those involved in curriculum development.

\section{Incoming Editor}

Finally, I have to tell you that this is my last issue as Chief Editor of Breathe. During these first 2 formative years, while an unofficial journal, the Editorship of this young educational journal has been under the care of the Chair of the ERS School. I have been proud to serve as Editor for this 2nd year and have thoroughly enjoyed the experience of working with so many talented individuals, including Editorial Board members, authors, reviewers, Managing Editors and other editorial staff. I thank them all for their invaluable contribu-

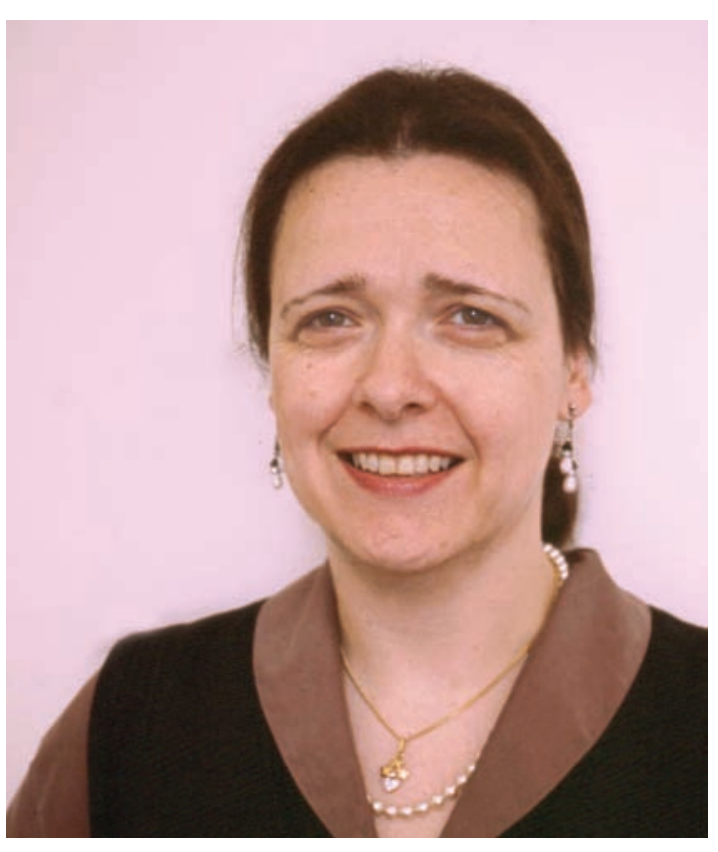
tion to the success of the journal. Now that the journal has become an official publication of the ERS, the Editorship must be separate so that sufficient time can be devoted to fulfil the aim to make this a world-leading CME journal. I am delighted to tell you that from a shortlist of excellent candidates, Anita Simonds (London, UK) has recently been appointed as the next Editor of Breathe to take over her position after the ERS Congress in Munich. She is a broad-based respiratory physician of international renown, highly regarded both for her editorial abilities and her major contribution to education. The journal will be safe in her hands and when she assumes her position as Chief Editor. I also look forward to welcoming her as the new Director for Breathe on the School Committee. I hope she will enjoy the position as much as I have.

I must conclude by giving special thanks to the editorial team, and in particular to the main Managing Editor Pippa Powell who is nothing short of superb and gave me all the support I could possibly need during my time as Editor. My special thanks also go to Jean-Luc Eiselé, whose efficiency and management skills are legendary.
Anita Simonds New Breathe Chief Editor 